\title{
WEAKNESS OF ELDEST SONS
}

\author{
Statistics of Physical Examinations at Amherst College Seem to Bear Out Theory \\ That Younger Sons are Physically Superior to the First-Born-Age of \\ Parents Does Not Appear to Exercise Much Influence.
}

John H. Chase, Youngstown, Ohio.

F

$\mathrm{EW}$ factors in constructive eugenics have been more emphasized during recent years than the desirability of large families among superior people; and this factor received particular attention when English biometrists published studies purporting to show, as one reason for the advantage of large families to society, that the elder, children were inferior to those who followed; and, consequently, that the general average of the family, if small, was considerably below what it would have been if larger.

Karl Pearson, of London, the most noted proponent of this theory, was convinced that first and second born children are on the average inferior to their later born brothers and sisters, not only physically, but mentally and morally as well. In his pamphlet on "The Problem of Practical Eugenics," Pearson said:

"If our observations are correct, and I believe them to be so, then the mental and physical condition of the first and second born members of the family is differentiated from that of the later members. They are of a more nervous and less stable constitution. We find that the neurotic, the insane, the tuberculous and the albinotic, are more frequent among the elder born. Dr. Goring's results from criminality show the same law. . . . In the tuberculous, the insane and criminal stocks, the first few members are weighted. But the result of this new law is remarkable. It means that if you reduce the size of the family, you will tend to decrease the relative proportion of the mentally and physically sound in the community."

A proposition of such direct application and popular interest naturally aroused widespread attention. T. B. Macaulay, a Montreal member of the American Genetic Association, critically analyzed the statistics, ${ }^{1}$ and declared that the conclusions drawn from them were a mere statistical fallacy. Others followed him, until the method of compiling the statistics on which the theory rests was to a large extent discredited.

This method was to take the records of some institution-a sanatorium or penitentiary, for example-as a basis. The inmates were questioned as to the number of children in the families to which they belonged, and their own order in the families. The number of first-born inmates was compared with the total number of first-born children in the families; and so on with the second, third and later born. The percentages thus found have been higher in the case of early born inmates than of later born. It has been pointed out, however, that this result has no significance, and must necessarily follow, because the younger members of families are, quite naturally, not as numerous as the older ones in groups of adults, whether such groups be undesirable, as the tuberculous, the insane or the criminal, or unobjectionable, as doctors, lawyers, clergymen, heavyweights, married men or fathers. By statistics compiled in this way, it is argued, it would be possible to "prove" that elder born children are superior to the younger born, quite as easily as that they are

\footnotetext{
'In the American Breeders' Magazine, Vol. II, no. 3, p. 165, July, 1911. He also called attention to the matter at the Eugenics Congress in London, 1912.
} 
inferior. The theory thus falls to the ground, in the opinion of many, from lack of proof.

With the desire to test the theory by a method which would obviate the objections raised against that of Pearson and his co-workers, I investigated the records of the physical examinations of students who have entered Amherst College for a number of years past. At this institution Dr. Edward Hitchcock was the first man in charge of a collegiate physical department in America to establish anthropometric measurements and strength tests. He worked out a system of examination which was so thorough that there has been found no reason for changing the tests in more than 40 years. Each incoming freshman class has been measured and tested in the same way during all that time.

Thus a disinterested and reliable means of making an investigation as to the comparative strength of brothers was furnished; and as all those included in the data are adults, to the extent at least of being old enough to enter college, the fallacy pointed out by Macaulay in Pearson's studies is here obviated.

With the cooperation of Amherst authorities, I secured a list of $\mathbf{5 8}$ sets of brothers, from the physical examination charts. A correspondence was conducted with these individuals, particularly with a view to learning the ages of their parents, and their own order in the fraternities. Some of these sets of brothers included three individuals; most of them only two. Some of the sets I was obliged to disregard, in various computations, for various reasons.

In grouping the records of strength tests, I found first-born brothers strongest in four cases, second-born brothers strongest in 12 cases, and third-born strongest in 28 cases. As the individuals concerned came to college at about the same age, on the average, it seems clear enough that first-born brothers who came to Amherst were weaker than their younger brothers who followed.

Handling the figures in a different way, it was found that first-born brothers made a total of 11,361 points in the strength tests, second born had 12,510, and third born 13,251. The average strength of each individual in each class was: first born, 494 points; second born, 544 points; third born, 576 points. Of course, with such a small group of men, a few exceptional individuals would make a considerable change in the totals, and we know that there were exceptional individuals. Nevertheless, the results are so consistent as to make me confident that in this case the comparative strength of the brothers is faithfully represented by these figures, which seem to indicate that secondborn sons were about one-tenth stronger than first-born sons, and that thirdborn sons were correspondingly stronger still.

Out of all the records taken, there were only 20 boys who made more than 600 points in the strength test on their entrance to the college, while there were only 14 who were below 450 . Suppose, then, we say that those below the 450 mark are weaklings, those about 525 normal, and those above 600 strong. This makes 75 points as the difference between a normal young man and a weakling on one side, and an exceptionally strong man on the other side.

And this is just about the difference in the average strength of the firstborn and third-born sons who entered Amherst College.

Taking only the two older of each of these sets of brothers, I added three more similar pairs for which the same data were available, and tested them on height and weight, as well as strength. Without going into details, I give the results:

Younger brothers were heavier in 24 cases; older brothers were heavier in 23 cases.

Younger brothers were taller in 22 cases; older brothers were taller in 25 cases.

Younger brothers were stronger in 30 cases; older brothers were stronger in 17 cases.

The interpretation of these results may afford room for some dispute; but as the disparity in strength is still marked, it seems to me merely to indicate that height and weight have little bearing on the question of strength or 
constitutional superiority. I believe this conclusion is not out of harmony with our observations on those about us in daily life.

Of course, statistics on this point are always open to the obvious explanation that children of immature parents are likely to be of inferior physique. That is an entirely different question, which depends on the age of the parents, and not on the order of birth, or the size of the family. However, in order to find whether any light was thrown on my results, I secured information from as many of the brothers as possible-30 pairs or 60 individuals - as to the ages of their parents, and then compared the records of the individual students with the ages of their parents when the individual was born.

Out of the 60 different cases, there were seven men who had records of over 700 points in their strength tests. The strongest man in the group totaled 859 points; I learned that his father was 40 years old and his mother 42 , at his birth. The second strongest had 809 points to his credit; the age of his father at the time of his birth was 49 years, and of his mother, 35 . Of the other five strong men, in order of rank, the ages of the parents were as follows:

Father 50, mother 30; father 33, mother 31 ; father 28 , mother 28 ; father 47 , mother 33 ; father 42 , mother 28 .

The average age of the fathers was 41 and of the mothers 32 .

I should be the last one to attempt to lay down any conclusions from such a small number of cases, but I may at least point out that these figures are unusual, if we accept the widely-quoted view that the best period for the production of children is. between 20 and 30 .

Summing the ages of the parents of the students whose strength I have called "normal," I found that the fathers averaged 38 and the mothers 31 years of age, at the birth of the sons in question. When the weakest students in our list were considered, their parents were found to have been, on the aver- age, 36 years old (father) and 30 (mother) at the time of their birth. In such a small group, the slight decrease in age of parents, correlated to weakness in sons, can hardly be held to have any significance; and that it has no significance in these figures is further indicated by another test I made to check it. I picked out all the parents who had their first child after they were 30 years old, and compared the strength records of these first children with the records of the other first born, who were born before their parents reached the age of 30. The children of older parents averaged 500 points against 494 for the children of younger parents-a difference so slight as to amount to identity. It is obvious, then, that as far as these cases are concerned, the age of the parents has little appreciable effect on the strength of their children; but it must be noted that practically all the parents under consideration were mature, and even considerably beyond the usual age for the beginning of parenthood.

The question whether first-born children are inferior is still far from settled. Assuming for the moment that they are inferior, we still have to seek a cause for such inferiority. One of the most popular explanations does not concern itself with heredity at all, but supposes that the younger children profit by being kept constantly on their mettle, in order to make a favorable showing in comparison with the older ones; the eldest, on the other hand, are not obliged greatly to exert themselves in competition with the younger ones. My investigation of these Amherst students does not, of course, pretend to settle any of the questions involved, but I offer it as a contribution which at least avoids the fallacy charged to Pearson. Summing up, it indicates that the eldest sons are physically weakest, and that this weakness has no relation to their weight or height. If the age of their parents at birth has any influence on the figure, it is slight. 